\title{
The Content of a Low-income, Uninsured Primary Care Population: Including the Patient Agenda
}

\author{
Larry B. Mauksch, MEd, Wayne J. Katon, MD, Joan Russo, PhD, \\ Suzanne M. Tucker, EdD, Edward Walker, MD, and Janet Cameron, MSW
}

Background: Poor and uninsured people have increased risk of medical and psychiatric illness, but they might be more reluctant to seek care than those with higher incomes. Little information exists about the biopsychosocial problems and concerns of this population in primary care.

Methods: We surveyed 500 consecutive patients (aged 18 to 64 years) in a primary care clinic serving only uninsured, low-income patients. We used self-report questions about why patients were coming to the clinic, a chronic illness questionnaire, the Primary Care Evaluation of Mental Disorders Patient Health Questionnaire, and items from the Childhood Trauma Questionnaire. Providers completed a questionnaire naming problems elicited from patients.

Results: Patients reported their most common chronic medical problems to be headaches, chronic back problems, and arthritis. The most common concerns patients wanted to discuss with providers and that providers elicited from patients were problems with mood. Compared with patients without current major mental illness, patients with a current major mental illness reported significantly $(P<.001)$ more concerns, chronic illnesses, stressors, forms of maltreatment and physical symptoms.

Conclusion: The illness content of this uninsured, low-income population is dominated by emotional distress and physical pain. These needs place a serious burden on providers and can complicate management of chronic medical illnesses. Recommendations for specialized interview training and integrating mental health services are discussed. (J Am Board Fam Pract 2003;16:278-89.)

People without health insurance often have different health-care-seeking behaviors than people who are insured. The uninsured are less likely to pursue care for acute illnesses, chronic illnesses, preventive care, or for serious or morbid symptoms ${ }^{1-3}$ Their hesitance to seek health care becomes apparent after short periods without health insurance and is more pronounced after extended uninsured periods. ${ }^{4,5}$ In midlife, those who are uninsured experience a greater decline in overall health status than those who are insured. ${ }^{6}$ The most vulnerable sec-

Submitted, revised, 12 September 2002.

From the Department of Family Medicine (LBM, WJK, EW), and the Department of Psychiatry and Behavioral Sciences (WJK, JR, EW), University of Washington School of Medicine, Seattle; and the Marillac Clinic (SMT, JC), Grand Junction, Colorado. Address reprint requests to Larry Mauksch, Family Medicine Residency, Box 354775, 4245 Roosevelt Way NE, Seattle, WA 98105.

Between August, 1998 and July, 1999 Mr. Mauksch was on leave from the University of Washington Department of Family Medicine as a Consultant in Collaborative Care to the Marillac Clinic. Funding for his position came from the Laura Jane Musser Fund, the Victim/Witness Assistance and Law Enforcement Fund-21st Judicial District of Colorado, the Sisters of Charity, and St. Mary's Hospital. Portions of this research were presented at the 2002 meeting of the Collaborative Family HealthCare Association, Clearwater, Florida. tors of the uninsured population are those persons living in poverty. In $2000,41 \%$ of the population living below federal poverty guidelines, aged 18 and 64 years, lacked health insurance. ${ }^{7}$

The relation between poverty and poor health is well established. ${ }^{89}$ Compared with middle- and upper-income populations, indigent populations have more medical illness and mental illness, diminished psychological, social, and physical functioning, ${ }^{10-12}$ and greater mortality rates. ${ }^{13,14}$ Those living in poverty, even when covered by health insurance, are more reluctant to seek health care than persons with higher incomes. ${ }^{15-17}$

These features of low-income and uninsured populations suggest that the characteristics of indigent, uninsured primary care populations might be different from general primary care populations. There is growing evidence to support this hypothesis. ${ }^{18-22}$ We could find only limited documentation, however, of the full content of medical or psychiatric problems, common co-occurring illnesses, or the reasons why patients in low-income uninsured, primary care populations seek care.

The present study builds on data from two earlier studies of an uninsured, low-income, primary 
care adult population. To better understand provider time use, we studied the frequency of diagnoses and of diagnostic combinations in all patient visits during a 1-year period between 1998 and 1999. ${ }^{23}$ The most common visit diagnoses recorded by providers were depression (23\%), hypertension (12\%), sinusitis $(7.4 \%)$, tobacco abuse $(6.7 \%)$ and anxiety $(6.0 \%)$. In one half of the visits, providers recorded two or more problems. Fifty percent of these multiple problem visits included depression, anxiety, or alcohol abuse. In a second study we surveyed 500 consecutive patients (only one visit per patient was included) to assess the prevalence of mental disorders and compared findings with results from a parallel study of 3,000 patients from a representative primary care sample. ${ }^{22}$ Twice as many low-income, uninsured primary care patients had mental disorders compared with the general primary care sample (34\% vs. $15 \%)$. Within the low-income sample, those with mental disorders had significantly more medical problems, lower functional status and greater disability than patients without mental disorders. Because our visit data included multiple visits by the same patients and our prevalence study only assessed mental disorders, we did not have a measure of the relative prevalence of all health care problems or of problem combinations.

In the current study, we sought to describe the biopsychosocial content of this population. Because middle- and high-income, insured people have different health-care-seeking behaviors than lowincome and uninsured people, we wanted to learn what concerns prompted them to seek care. Because mental disorders are so prominent in this population and because they often complicate overall health care efforts, we studied which problems were most associated with mental disorders. We believed this information would be helpful in designing health care efforts to respond to the unique needs of poor, uninsured working-age patients seeking primary health care.

\section{Methods}

\section{Setting}

This study was conducted in April and May of 1999 at the Marillac Clinic serving Grand Junction, Colo, and the surrounding Mesa County. At the time of this study, Marillac Clinic served only those with incomes of less than $150 \%$ of federal poverty guidelines and who had no form of health insurance (no Medicaid, no Medicare). In 1999 Mesa County had a population of 113,$000 ; 14.5 \%$ lived below the poverty level, $16 \%$ lacked health insurance, $90 \%$ were white, and $8 \%$ were Hispanic. ${ }^{24}$ The Human Subjects Review committee of St. Mary's Hospital, Grand Junction, approved our study. St. Mary's Hospital, the regional medical center for Western Colorado, is adjacent to and closely affiliated with the Marillac Clinic.

\section{Selection and Description of Patients}

All consecutive patients (patients with repeated visits were excluded) aged 18 years and older who spoke English or Spanish and with clinic medical appointments were invited to participate. Participants were given a $\$ 5$ coupon to a grocery store. Five hundred eighty-nine patients were invited, 68 refused, and 21 were missed, for an enrollment of 500 patients $(85 \%)$. This was $19 \%$ of the patients seen in 1999. The mean age (SD) of those who refused was 40 (11.2) years compared with $38(12.1)$ years for participants, $(t(588)=1.88)$, and $59 \%$ of those who refused were women compared with $68 \%$ of participants $\left(\chi^{2}=2.42 ; d f=1\right)$. More information about the enrollment procedures is available elsewhere. ${ }^{22}$

\section{Data Collection}

\section{Patients}

Before seeing their provider Marillac patients completed a questionnaire. During consent, patients could approve or not allow providers to be given information from the survey. Providers were not allowed to see patient responses until after the visit, however. Patients were asked to "please list all the health concerns you hoped to discuss with your medical provider today."

The questionnaire included the Primary Care Evaluation of Mental Disorders Patient Health Questionnaire (PRIME-MD PHQ). ${ }^{25}$ The PHQ includes a question asking, "During the last 4 weeks, how much have you been bothered by any of the following problems?" to assess the presence of 13 physical symptoms. Response options were (1) not bothered, (2) bothered a little, (3) bothered a lot. One question on the PHQ assessed physical and sexual abuse, and we divided it into two questions, one assessing physical abuse since age 18 years and the other assessing sexual abuse since age 18 years. The PHQ includes a section assessing 
whether patients were not bothered, bothered a little, or bothered a lot by up to 10 current stressors in the last 4 weeks. The PHQ assesses the presence of four threshold disorders: major depression, anxiety, panic disorder, or bulimia without physician involvement in assessment. The term threshold refers to meeting criteria for DSM IV disorders. More details about the use of these questions and population percentages with each diagnosis are described in our earlier study ${ }^{22}$ and in the PHQ validation study. ${ }^{25}$

To assess risk for childhood maltreatment, we used seven items taken from the Childhood Trauma Questionnaire, a valid and reliable measure of early abuse and neglect. ${ }^{26}$ Although we were not able to include the entire instrument, these seven questions had the highest item-total correlations with the five subscales (emotional abuse, physical abuse, sexual abuse, emotional neglect, and physical neglect) based on a secondary analysis of a large primary care population. ${ }^{27}$ Respondents are presented with a series of statements about childhood experiences that are endorsed on a 5-point Likert-type scale, with response options ranging from never true to very often true. One question, used elsewhere, ${ }^{28}$ assessed the presence of 16 current chronic illnesses. Other questions assessed demographic variables.

When patients consented, all diagnostic information was given to their primary care provider after the visit for use in the next visit. All patients endorsing any level of suicidal ideation were called by their primary care provider or the first author (LBM).

\section{Providers}

Before the visit, providers were given a separate sheet of paper with the patient's chart and asked to "please list all problems and concerns you have elicited." Providers filled out these sheets during and after the visit and placed them in a collection box in the provider work area. Numbers were placed on the pages that matched numbers on the patient questionnaire so they could be combined for analysis.

\section{Problem Coding}

The clinic database was queried to find the 30 most frequent diagnoses. This list was compared against the top diagnoses in the National Ambulatory Medical Care Survey (NAMCAS) ${ }^{29}$ with missing items added. The resulting list was integrated into the 17 global categories from the International Classification of Diseases, $9^{\text {th }}$ Edition (ICD-9) ${ }^{30}$ to create global categories for those not covered by the specific Marillac and NAMCAS items, including categories for signs, symptoms, and ill-defined conditions. We added three items: medication check or refill, socioeconomic concerns (eg, "no money for medicine" or "can't pay rent"), and other tests. The final list of 58 items was used to categorize patient responses about concerns they wanted to discuss on the day of their visit and provider elicitation of patients' concerns. The first author or a nurse categorized responses on all the surveys. The clinic medical director clarified coding questions. The list of the 58 categories is available from the first author.

\section{Analysis}

The entire patient sample was analyzed as a single unit to describe the relative prevalence of all problems and concerns. The sample was also analyzed to compare two subgroups-those meeting criteria for threshold diagnoses and those not meeting criteria for threshold diagnoses. This subgroup analysis was performed because in our earlier study ${ }^{22}$ we found that the threshold group had considerably lower functional status, greater disability, and higher counts of medical problems than patients who did not have a threshold disorder. One hundred sixty-eight patients (34\% of the 500 patients sampled) met threshold criteria for one or more diagnoses. $^{22}$

To test differences in demographics between patients with and without threshold diagnoses, chisquare analyses with corrections for continuity and $t$ tests were used for categorical and continuous variables, respectively. Odds ratios (ORs) and 95\% confidence intervals (CIs) were constructed to examine the odds of endorsing a particular health problem, concern, stressor, or maltreatment items in the group of patients with a threshold diagnosis in comparison with those without a threshold diagnosis. $t$ Tests were used to determine whether the number of chronic health problems, concerns, elicited concerns, stressors, and endorsed maltreatment items differed between the threshold groups. Lastly, a logistic regression analysis was performed to determine which item counts best discriminated between patients with and without a threshold diagnosis. Backward and forwards stepwise tech- 
Table 1. Demographics of Study Population $(n=500)$.

\begin{tabular}{lc}
\hline Characteristic & Value \\
\hline & Mean (range) \\
Age, years & $38(18-64)$ \\
& Percent \\
Female & 68.0 \\
Marital status & \\
Single & 23.6 \\
Married & 31.8 \\
Divorced & 31.0 \\
Separated & 7.4 \\
Widowed & 4.0 \\
Education & \\
$<8$ th grade & 6.6 \\
Some high school & 17.8 \\
High school graduate & 37.2 \\
College & 30.8 \\
College graduate & 5.6 \\
Ethnicity & \\
White & 74.6 \\
Hispanic & 14.2 \\
Native & 5.2 \\
Other & 3.0 \\
Personal income (\$) & \\
0-5,000 & \\
5,000-10,000 & \\
10,000-15,000 & 41.0 \\
15,000-20,000 & 31.0 \\
$>20,000$ & 16.0 \\
\hline & 8.0 \\
\hline & 4.0 \\
\hline
\end{tabular}

niques were used to arrive at the set of independently significant predictors $(P<.05)$. The odds ratios for the analyses represent the increase in odds associated with a 1-point increase in the count.

\section{Results}

Table 1 displays the population demographics. We compared the demographic variables (age, education, martial status, ethnicity, household size, household income, and personal income) in the patients who met criteria for threshold diagnoses and patients in the rest of the population. We found no significant differences except in personal income. Forty-three percent of patients reporting incomes less than $\$ 5,000$ a year had one or more threshold disorders compared with $29 \%$ of patients with incomes greater than $\$ 5,000$ per year $\left(\chi^{2}=\right.$ 9.09; $d f=1 ; P<.003)$.

Table 2 shows patient reports of current chronic illnesses. Pain-related illnesses are the most frequent problems. Seven of the 10 most common illnesses are reported by a higher percentage of patients with one or more threshold diagnoses. The population percentages for other health problems not in the table are physical disability, such as loss of an arm or leg or eyesight or hearing or a birth defect, $6.5 \%$; chronic liver disease, $6.1 \%$; angina, heart failure, or coronary artery disease, $4.0 \%$; neurological condition, such as epilepsy, convulsions,

Table 2. Percentage of Patients Responding to the Request to Indicate Whether They Now Have Any of the Following Health Problems.

\begin{tabular}{|c|c|c|c|c|}
\hline Health Problem & $\begin{array}{c}\text { Total } \\
\text { Population } \\
(\mathrm{n}=500)\end{array}$ & $\begin{array}{c}\text { Patients Without } \\
\text { Threshold } \\
\text { Diagnosis } \\
(\mathrm{n}=332)\end{array}$ & $\begin{array}{c}\text { Patients With } \\
\text { Threshold } \\
\text { Diagnosis* } \\
(\mathrm{n}=168)\end{array}$ & $\begin{array}{l}\text { Odds Ratio } \\
(95 \% \mathrm{CI})\end{array}$ \\
\hline Migraine or other severe chronic headaches & 33.7 & 28.1 & 44.9 & $2.1^{\dagger}(1.4-3.1)$ \\
\hline Chronic back problems (including disk or spine) & 32.6 & 25.1 & 48.0 & $2.8^{\dagger}(1.8-4.2)$ \\
\hline Arthritis or rheumatism & 29.2 & 22.8 & 42.0 & $2.4^{\dagger}(1.6-3.8)$ \\
\hline Hypertension or high blood pressure & 21.5 & 18.6 & 27.6 & $1.7^{\ddagger}(1.1-2.7)$ \\
\hline Asthma & 19.5 & 18.6 & 21.1 & $1.2(0.7-1.9)$ \\
\hline Stomach ulcer, chronic inflamed bowel, enteritis, colitis & 15.2 & 11.1 & 23.8 & $2.5^{\dagger}(1.5-4.2)$ \\
\hline Diabetes or high blood glucose & 15.1 & 12.9 & 19.7 & $1.6(0.9-2.9)$ \\
\hline $\begin{array}{l}\text { Breathing trouble, caused by emphysema or chronic } \\
\text { lung disease }\end{array}$ & 10.4 & 7.3 & 16.4 & $2.5^{\S}(1.4-4.7)$ \\
\hline Problems urinating or bladder infections & 10.1 & 8.2 & 13.8 & $1.8(0.99-3.3)$ \\
\hline $\begin{array}{l}\text { Women's health problems (severe cramps, heavy bleeding, } \\
\text { problems with menopause) (women only) }\end{array}$ & 26.2 & 19.3 & 39.3 & $2.7^{\dagger}(1.6-4.5)$ \\
\hline
\end{tabular}

*Threshold diagnosis means the patient has at least one of the following diagnoses: major depression or generalized anxiety or panic disorder or bulimia.

${ }^{\ddagger} P<.05$.

${ }^{\dagger} P<.001$.

${ }^{\$} P<.01$. 
Table 3. What Patients Want to Discuss and What Providers Elicit from Their Patients.

\begin{tabular}{|c|c|c|c|c|c|c|}
\hline \multirow[b]{2}{*}{ Concern } & \multicolumn{3}{|c|}{$\begin{array}{l}\text { Concerns Patient Hoped to } \\
\text { Discuss With Provider }\end{array}$} & \multicolumn{3}{|c|}{$\begin{array}{l}\text { Provider List of Problems and } \\
\text { Concerns Elicited From Patients }\end{array}$} \\
\hline & $\begin{array}{l}\text { Percent of } \\
\text { Patients } \\
(\mathrm{n}=500)\end{array}$ & $\begin{array}{c}\text { Percent of Patients } \\
\text { Without/With } \\
\text { Threshold* } \\
\text { Diagnoses } \\
(\mathrm{n}=332 / 168)\end{array}$ & $\begin{array}{l}\text { Odds Ratio } \\
\text { (95\% CI) }\end{array}$ & $\begin{array}{l}\text { Percent of } \\
\text { Patients } \\
(\mathrm{n}=500)\end{array}$ & $\begin{array}{c}\text { Percent of } \\
\text { Patients } \\
\text { Without/With } \\
\text { Threshold* } \\
\text { Diagnoses } \\
(\mathrm{n}=332 / 168)\end{array}$ & $\begin{array}{l}\text { Odds Ratio } \\
(95 \% \text { CI })\end{array}$ \\
\hline Problems with mood & 29.2 & $19.6 / 48.2$ & $3.8^{\dagger}(2.5-5.7)$ & 9.8 & $6.9 / 15.5$ & $2.5^{\ddagger}(1.4-4.5)$ \\
\hline Hypertension & 12.0 & $12.0 / 11.9$ & $1.0(0.6-1.7)$ & 9.0 & $8.7 / 9.5$ & $1.1(0.6-2.1)$ \\
\hline Anxiety stress & 9.2 & $5.1 / 17.3$ & $3.9^{\dagger}(2.1-7.3)$ & 6.4 & $1.5 / 16.1$ & $12.5^{+}(4.7-33.2)$ \\
\hline Tobacco dependence & 8.2 & $9.6 / 5.4$ & $0.5(0.2-1.1)$ & 1.0 & $1.2 / 0.6$ & $0.5(0.1-4.4)$ \\
\hline Skin concern & 8 & $7.8 / 10.1$ & $1.3(0.7-2.5)$ & 7.0 & $6.3 / 8.3$ & $1.3(0.7-2.7)$ \\
\hline Headaches & 7.8 & $7.8 / 7.7$ & $1.0(0.5-2.0)$ & 8.4 & $6.6 / 11.9$ & $1.9(1.0-3.6)$ \\
\hline Sinusitis & 7.8 & $6.9 / 9.5$ & $1.4(0.7-2.8)$ & 5.2 & $5.7 / 4.2$ & $0.7(0.03-1.7)$ \\
\hline Diabetes & 7.4 & $7.5 / 7.1$ & $0.9(0.5-1.9)$ & 6.4 & $5.7 / 7.7$ & $1.4(0.7-2.9)$ \\
\hline Back Disorders & 7.2 & $5.4 / 10.7$ & $2.1^{\S}(1.1-4.1)$ & 8.0 & $6.3 / 11.3$ & $1.9(1.0-3.6)$ \\
\hline Medication refill or check & 7.2 & $6.3 / 8.9$ & $1.4(0.7-2.9)$ & 10.6 & $8.4 / 14.9$ & $1.9^{\ddagger}(1.1-3.4)$ \\
\hline
\end{tabular}

*Threshold diagnosis means the patient has at least one of the following diagnoses: major depression or generalized anxiety or panic disorder or bulimia.

${ }^{\dagger} P<.001$.

${ }^{\ddagger} P<.01$.

${ }^{\circledR} P<.05$

fainting spells, or Parkinson's disease, $2.7 \%$; stroke or major paralysis, $2.3 \%$; Cancer diagnosed within the last 3 years but not skin cancer, $2.1 \%$.

Table 3 shows the frequencies of the concerns patients hoped to discuss on the day of the visit and the concerns and problems providers elicited from their patients. Not reported in the table are assorted signs, symptoms, and ill-defined conditions that patients hoped to discuss and that providers elicited. Thirty-eight percent of patients and 33\% of providers reported one or more symptoms, making this category the largest of responses. There was no significant difference between the percentage of patients with threshold diagnoses $(42 \%)$ or patients without threshold diagnoses $(36 \%)$ indicating hopes to discuss one or more symptoms $(\mathrm{OR}=1.3,95 \%$ CI, 0.9-1.9). Providers elicited one or more symptoms from a higher percentage of patients in the threshold group than in the nonthreshold group, however, $42 \%$ vs $29 \%$, (OR = 1.7, 95\% CI, 1.2-2.5; $P<.01$ ).

Table 4 shows the prevalence of common stressors bothering patients a lot. Financial concerns are most common, and all stressors are reported significantly more often in patients with major mental disorders. Table 5 shows patient reports about physical and sexual violence in adulthood and emo- tional, social, physical, and sexual maltreatment during years when patients were growing up. All forms of maltreatment during adulthood and childhood are more common in patients with mental disorders.

Table 6 examines the relation between numbers of items endorsed and the presence of a mental disorder. Patients with mental disorders endorsed significantly more items for all variables in Tables 1 through 4 and on the symptom checklist in the PRIME-MD PHQ ${ }^{25}$ (not shown). Logistic regression analysis of the six total scores showed that item count increases in any one of four categories (patient concerns, stressors, maltreatment items, and physical symptoms) were significant independent predictors of having a threshold diagnosis.

\section{Discussion}

Patients in this low-income, uninsured primary care population report their most common chronic health problems to be headaches, chronic back problems and arthritis. A problem with mood was the most common, single health problem patients wanted to discuss with their providers $(29 \%)$ and that providers elicited $(9.8 \%)$ from their patients. Consistent with studies of symptom complaints in 
Table 4. Patients Indicating Whether They Have Been Bothered by Any of the Following Problems (Stressors) in the Last 4 Weeks.

\begin{tabular}{|c|c|c|c|c|}
\hline Problem (Stressor) & $\begin{array}{c}\text { Percent } \\
\text { of Total } \\
\text { Population } \\
(\mathrm{n}=500)\end{array}$ & $\begin{array}{c}\text { Percent of Patients } \\
\text { Without } \\
\text { Threshold } \\
\text { Diagnoses } \\
(\mathrm{n}=332)\end{array}$ & $\begin{array}{l}\text { Percent of } \\
\text { Patients With } \\
\text { Threshold } \\
\text { Diagnosis } \\
(\mathrm{n}=168)\end{array}$ & $\begin{array}{l}\text { Odds Ratio* } \\
(95 \% \mathrm{CI})\end{array}$ \\
\hline Financial problems or worries & 42.6 & 30.3 & 66.7 & $4.6(3.1-6.9)$ \\
\hline Concerns about weight; how you look & 35.3 & 25.9 & 53.3 & $3.6(2.2-4.9)$ \\
\hline Worrying about your health & 29.4 & 18.2 & 51.5 & $4.8(3.2-7.3)$ \\
\hline Something bad happened recently & 21.7 & 12.4 & 39.4 & $4.6(2.9-7.3)$ \\
\hline No one to turn to when you have problems & 19.2 & 9.3 & 38.3 & $6.1(4.0-10.0)$ \\
\hline Stress at work or school & 16.9 & 10.4 & 29.6 & $3.6(2.2-6.0)$ \\
\hline Stress in caring for family members & 16.7 & 9.1 & 31.6 & $4.6(2.8-7.7)$ \\
\hline Difficulties with spouse or partner & 16.5 & 8.9 & 31.2 & $4.6(2.8-7.8)$ \\
\hline $\begin{array}{l}\text { Thinking or dreaming about something terrible } \\
\text { that happened to you in the past }\end{array}$ & 12.1 & 3.9 & 27.8 & $9.5(4.9-18.6)$ \\
\hline Little or no pleasure during sex & 9.2 & 5.2 & 17.2 & $3.8(1.9-7.2)$ \\
\hline
\end{tabular}

Note: Response options were "not bothered," "bothered a little," and "bothered a lot." Only patients endorsing "bothered a lot" are included in the table.

*All odds were significant at $P<.001$

primary care, ${ }^{31,32}$ patients with current major mental illness reported significantly higher counts of current chronic illnesses, physical symptoms, maltreatment experiences, and current stressors and they had significantly more concerns to discuss and significantly more concerns elicited. Increasing item counts in any one of four variables (patient concerns, stressors, maltreatment items, and physical symptoms) was an independent predictor of mental illness. An examination of these patients'

Table 5. Patient Reports of Maltreatment During Adulthood or Childhood.

\begin{tabular}{|c|c|c|c|c|}
\hline Form of Maltreatment* & $\begin{array}{l}\text { Percent of Total } \\
\text { Population } \\
(\mathrm{n}=500)\end{array}$ & $\begin{array}{c}\text { Percent of Patients } \\
\text { Without a Threshold } \\
\text { Diagnosis } \\
(\mathrm{n}=332)\end{array}$ & $\begin{array}{l}\text { Percent of Patients } \\
\text { With a Threshold } \\
\text { Diagnoses } \\
(\mathrm{n}=168)\end{array}$ & $\begin{array}{l}\text { Odds Ratio } \\
(95 \% \mathrm{CI})\end{array}$ \\
\hline $\begin{array}{l}\text { Ever been hit, slapped, kicked or other hurt } \\
\text { since age } 18 \text { years }\end{array}$ & 52.3 & 44.5 & 67.9 & $2.6(1.8-3.9)$ \\
\hline Forced, unwanted sexual act since 18 years & 21.3 & 16.8 & 30.5 & $2.2(1.4-3.4)$ \\
\hline \multicolumn{5}{|l|}{ When I was growing up: } \\
\hline $\begin{array}{l}\text { My family was (never or rarely) a source of } \\
\text { strength and support }\end{array}$ & 49.1 & 41.6 & 63.5 & $2.4(1.7-3.6)$ \\
\hline I had a fear of being hurt by family member ${ }^{\ddagger}$ & 22.2 & 13.0 & 40.1 & $4.5(2.9-7.0)$ \\
\hline $\begin{array}{l}\text { Someone attempted sexual touching or asked } \\
\text { me to touch }\end{array}$ & 19.8 & 11.3 & 36.4 & $4.5(2.8-7.2)$ \\
\hline A family member hated $\mathrm{me}^{\ddagger}$ & 16.4 & 9.6 & 29.5 & $3.9(2.4-6.5)$ \\
\hline $\begin{array}{l}\text { A family member hit me so hard it left } \\
\text { bruises of marks }\end{array}$ & 16.2 & 9.6 & 28.9 & $3.8(2.3-6.3)$ \\
\hline $\begin{array}{l}\text { Someone threatened to hurt me or tell lies } \\
\text { unless I did something sexual }{ }^{\ddagger}\end{array}$ & 10.7 & 5.9 & 20.0 & $4.0(2.2-7.3)$ \\
\hline $\begin{array}{l}\text { My parents were too drunk or high to take } \\
\text { care of the family }\end{array}$ & 8.0 & 4.7 & 14.5 & $3.5(1.8-6.8)$ \\
\hline
\end{tabular}

Note: All threshold percentages are significantly greater than nonthreshold percentages, $P<.001$.

*Response options included: never true, rarely true, sometimes true, often true, and very often true.

${ }^{\dagger}$ Only responses marked as never true or rarely true.

${ }^{\ddagger}$ Only responses marked as often true or very often true. 


\begin{tabular}{|c|c|c|c|c|c|c|}
\hline \multirow[b]{2}{*}{ Variable } & \multicolumn{2}{|c|}{$\begin{array}{l}\text { Item Counts in } \\
\text { Patients Mean (SD) }\end{array}$} & \multirow[b]{2}{*}{$\begin{array}{c}t \text { Test* } \\
d f=498\end{array}$} & \multicolumn{3}{|c|}{$\begin{array}{c}\text { Logistic Regression Analysis: Total } \\
\text { Counts and Odds of a Threshold } \\
\text { Diagnosis }\end{array}$} \\
\hline & $\begin{array}{l}\text { Without } \\
\text { Threshold } \\
\text { Disorder }\end{array}$ & $\begin{array}{l}\text { With } \\
\text { Threshold } \\
\text { Disorder }\end{array}$ & & $\begin{array}{l}\text { Beta } \\
\text { Coefficient }\end{array}$ & Wald's $t$ & $\begin{array}{l}\mathrm{Odds}^{\dagger} \\
(95 \% \mathrm{CI})\end{array}$ \\
\hline $\begin{array}{l}\text { Patient report of current chronic health problems } \\
\text { (from Table 1) }\end{array}$ & $1.7(1.7)$ & $3.1(2.3)$ & 6.71 & - & - & - \\
\hline $\begin{array}{l}\text { Number of concerns that patients hoped to discuss } \\
\text { with their health provider (from Table 2) }\end{array}$ & $2.4(1.3)$ & $2.9(1.4)$ & 4.02 & 0.23 & $6.14^{\ddagger}$ & $1.3(1.1-1.5)$ \\
\hline $\begin{array}{l}\text { Number of problems and concerns elicited by } \\
\text { providers (from Table } 3 \text { ) }\end{array}$ & $1.7(1.3)$ & $2.5(1.4)$ & 5.51 & - & - & - \\
\hline $\begin{array}{l}\text { Bothered a lot in the last } 4 \text { weeks by one or more } \\
\text { stressors (from Table } 4 \text { ) }\end{array}$ & $1.3(1.6)$ & $3.7(2.2)$ & 2.90 & 0.49 & $54.83^{\S}$ & $1.6(1.4-1.9)$ \\
\hline $\begin{array}{l}\text { Number of positively endorsed maltreatment items } \\
\text { (from Table 5) }\end{array}$ & $1.5(1.6)$ & $3.3(2.4)$ & 8.45 & 0.22 & $13.48^{\S}$ & $1.3(1.1-1.4)$ \\
\hline $\begin{array}{l}\text { In the last } 4 \text { weeks, the number of symptoms } \\
\text { bothering patients a lot (from PRIME-MD PHQ } \\
\text { symptom checklist) }\end{array}$ & $1.3(1.5)$ & $2.9(2.2)$ & 8.43 & 0.21 & $10.40^{\S}$ & $1.2(1.1-1.4)$ \\
\hline
\end{tabular}

*All threshold means are significantly greater than nonthreshold percentages, $P<.001$.

${ }^{\dagger}$ Odds increase per 1-point increase in total score.

${ }^{\ddagger} P<.01$.

${ }^{\$} P<.001$.

PRIME-MD PHQ_-Primary Care Evaluation of Mental Disorders Patient Health Questionnaire.

current stressors and maltreatment history provides insight into this population's psychosocial morbidity highlighting financial strain, social and family stress, violence, and sexual abuse in childhood and adulthood.

The most prevalent patient health concerns in this population are mental disorders and various forms of chronic pain, and these two illnesses are likely to occur in patients at the same time. One recent large nationally representative study in the United States used the same question as we did to assess prevalence of chronic medical illnesses. They found pain complaints to be the largest illness category across all socioeconomic strata, with population percentages inversely proportional to family income. ${ }^{33}$ The high prevalence of pain-related problems (headaches, back pain, gynecological pain) in patients with mental disorders (and vice versa) is consistent with evidence showing that patients with persistent pain are more likely to have concurrent depression or anxiety. ${ }^{34,35}$ Patients with depression and anxiety have also been found to have a higher prevalence of medically unexplained symptoms, particularly pain. ${ }^{32}$

The well-established trend for most patients to use general medical providers as their de facto ${ }^{36,37}$ mental health providers might be more pronounced for a low-income population with mental disorders. Recent evidence suggests they might be more likely to lose insurance coverage or have benefits decreased. ${ }^{38,39}$ Addressing these problems might be an essential component for improving the health and well-being of this population. Mental illness is associated with more disability ${ }^{40,41}$ than most biomedical problems and can impede efforts to manage common medical illnesses, such as hypertension and diabetes. ${ }^{42-44}$

The needs of this population present a formidable challenge to health care providers who might have limited time, training, and interest to address psychosocial problems. ${ }^{45,46}$ Current pressures to see more patients, fill out more forms, yet provide high-quality, evidence-based care make addressing these needs difficult. Workable solutions should accommodate the provider's as well as the patient's needs if changes are to be lasting and effective. The recent Institute of Medicine recommendations, Crossing the Quality Chasm: A New Health Care System for the $21^{\text {st }}$ Century, ${ }^{47}$ provides some recommendations that can help both patients and providers. Two of its 10 core recommendations are for providers to share decision making with patients 
and for clinicians to cooperate with one another. Below we discuss these recommendations in light of this study's findings, keeping in mind that any changes should enhance rather than complicate the lives of indigent-care providers.

Using communication skills ${ }^{48}$ that emphasize shared decision making throughout the interview improves health outcomes and conserves resources, ${ }^{49,50}$ helps manage time, ${ }^{51-53}$ and can be especially important in serving a population that feels little control in day-to-day life. An element long recognized as essential to effective communication is discovering the reason(s) for the patient visit. ${ }^{54}$ Patients with long problem lists and mental disorders, however, are often seen as difficult $t^{55}$ or frustrating ${ }^{56}$ by physicians who do not want to lose control of time and who have limited training to treat mental health problems. Training providers to be proactive in eliciting a full list of patient concerns up front, in combination with time-management strategies (eg, prioritization, negotiation), can help providers feel comfortable in collaborative agenda setting, knowing visit lengths need not be longer. ${ }^{57}$

Making an effort at the beginning of the interview to elicit all patient concerns has several advantages. Our results are consistent with other studies of patients who have multiple medically unexplained symptoms, ${ }^{58,59}$ suggesting that many patients will acknowledge emotional pain if given the opportunity. Counting patient complaints during a full elicitation of patient concerns may serve as a simple screen for mental illness. ${ }^{60}$ The US Preventive Services Task Force now recommends screening for depression in primary care. ${ }^{61}$ This practice can be especially valuable in underserved settings. A full understanding of patient concerns up front might decrease the probability of "Oh, by the way" comments in the closing moments of the interview. ${ }^{51}$ When patients prioritize the management of current chronic illness lower than psychosocial issues, physicians gain valuable insight into patient readiness to address problems that might be of greater importance to providers than to patients. Patients who feel that all their concerns and expectations $^{62,63}$ are addressed and that their preferences $^{64,65}$ influence decision making are more satisfied and have better health outcomes. ${ }^{50,62}$ Addressing indigent patient expectations might help providers establish a foundation for a relation- ship from which subsequent efforts can be devoted to preventive and chronic health care. ${ }^{66}$

Earlier we reported that $90 \%$ of the Marillac patients preferred their mental health providers and medical providers communicate with one another about their care. ${ }^{22}$ Sharing the care of complicated patients can ease the burden on providers and improve the care for patients. Models that integrate mental health practitioners into primary care $^{67-69}$ have been shown to be effective in reducing symptoms, ${ }^{28,70}$ and cost-effective ${ }^{71-73}$ in reducing patient disability and risk of unemployment. ${ }^{72,74,75}$ The recent Surgeon General's report on mental health advocated for integration of mental health and primary care services as essential in improving health care outcomes in the United States. ${ }^{76}$ Similar collaborative and multifaceted approaches can be useful for patients with persistent pain. ${ }^{77}$ Systems serving a low-income, uninsured population can also benefit from hiring a case manager with strong community connections to assist with self-sufficiency concerns. ${ }^{78,79}$ Poverty plus financial strain ( $40 \%$ of this sample, $66 \%$ of patients with psychiatric illness) contribute to the incidence and maintenance of unemployment and psychiatric illness. ${ }^{12,80}$ Transforming health care systems to sustain efforts to address chronic illnesses, however, requires adjustment in multiple domains. ${ }^{23,81-83}$

\section{Limitations}

The Marillac Clinic population is mostly white and located in a semi-rural setting and might not be representative of often more diverse urban populations. Although our results suggest that the content of a low-income, uninsured primary care population is different from what has been reported in general primary care ${ }^{29,84}$ more research is needed. Earlier studies of the content of primary care use provider billing data that might not include all secondary diagnoses, such as psychosocial problems and chronic illnesses. ${ }^{85}$ Patients might have underreported or overreported concerns on survey questions or might write down more concerns than they express verbally. Providers might not have allowed patients to complete their agendas ${ }^{52,86}$ or they might have screened patient responses in some other way. We asked providers to list problems they elicited, which might not be the same as the problems they addressed or recorded in medical records. Some of the Marillac providers had received training in patient-centered interviewing. 
Studies in settings where providers are not trained in patient-centered skills might show a greater discrepancy between patient concerns and concerns the provider elicited.

Further studies using the same methods in both general primary care and underprivileged settings are needed to make accurate comparisons of the prevalence of common illnesses and patient concerns. Studies using direct observation will shed more light on the dynamics of the provider-patient relationship in indigent care settings.

\section{Conclusion}

Patients who lack health insurance and live in poverty often seek health care because they suffer emotional and physical pain. Without care, these patients are more likely to experience declining health, prolonged disability, and unemployment. Health care systems serving a low-income uninsured population might be more effective when integrating multifaceted, interdisciplinary approaches. Physicians who support patient autono$\mathrm{my}^{87,88}$ through shared agenda setting and treatment planning can provide to their indigent patients a health ingredient often absent in their worlds—a sense of control in life. ${ }^{89,90}$

The authors wish to thank the Marillac Clinic medical assistants, administrative staff, community volunteers, and clinicians who contributed to this study in many essential ways. Because no additional financial support was used to fund this study, the role of the entire clinic community was critical for successful completion of the study. We thank the Marillac patients for taking the time to describe their health care needs. We also thank Mark Doescher, MD, Barry Saver, MD., and Sharon Dobie, MD for their help with the conceptual phase of this work. Jurgen Unutzer, MD, helped us find the chronic illness questionnaire and Robert Spitzer, MD, helped us with the PRIME-MD PHQ.

The Marillac Clinic and the Mesa County Consortium on Health expresses their appreciation for support from the Robert Wood Johnson 2000 Local Initiative Funding Partners Program to match funding from local contributors lead by the Colorado Trust. This funding provides 4 years of funding for training and clinical service to better meet the needs of this population.

\section{References}

1. Baker DW, Shapiro MF, Schur CL. Health insurance and access to care for symptomatic conditions. Arch Intern Med 2000;160:1269-1274.

2. Weissman JS, Stern R, Fielding SL, Epstein AM. Delayed access to health care: risk factors, reasons, and consequences. Ann Intern Med 1991;114: $325-31$.
3. Hafner-Eaton C. Physician utilization disparities between the uninsured and insured. Comparisons of the chronically ill, acutely ill, and well nonelderly populations. JAMA 1993;269:787-92.

4. Ayanian JZ, Weissman JS, Schneider EC, Ginsburg JA, Zaslavsky AM. Unmet health needs of uninsured adults in the United States. JAMA 2000;284:2061-9.

5. Broyles RW, Narine L, Brandt EN Jr. The temporarily and chronically uninsured: does their use of primary care differ? J Health Care Poor Underserved 2002;13:95-111.

6. Baker DW, Sudano JJ, Albert JM, Borawski EA, Dor A. Lack of health insurance and decline in overall health in late middle age. N Engl J Med 2001;345: 1106-12.

7. US Census Bureau. Poor people without health insurance. Available at: http://www.census.gov/hhes/ hlthins/hlthin00/hi00tb.html.

8. Feinstein JS. The relationship between socioeconomic status and health: a review of the literature. Milbank Q 1993;71:279-322.

9. Fein O. The influence of social class on health status: American and British research on health inequalities. J Gen Intern Med 1995;10:577-86.

10. Lynch JW, Kaplan GA, Shema SJ. Cumulative impact of sustained economic hardship on physical, cognitive, psychological, and social functioning. N Engl J Med 1997;337:1889-95.

11. Hemingway H, Nicholson A, Stafford M, Roberts R, Marmot M. The impact of socioeconomic status on health functioning as assessed by the SF-36 questionnaire: the Whitehall II Study. Am J Public Health 1997;87:1484-90.

12. Bruce ML, Takeuchi DT, Leaf PJ. Poverty and psychiatric status. Longitudinal evidence from the New Haven Epidemiologic Catchment Area study. Arch Gen Psychiatry 1991;48:470-4.

13. Lynch JW, Kaplan GA, Pamuk ER, et al. Income inequality and mortality in metropolitan areas of the United States. Am J Public Health 1998;88: 1074-80.

14. Backlund E, Sorlie PD, Johnson NJ. A comparison of the relationships of education and income with mortality: the National Longitudinal Mortality Study. Soc Sci Med 1999;49:1373-84.

15. Hayward RA, Shapiro MF, Freeman HE, Corey CR. Inequities in health services among insured Americans. Do working-age adults have less access to medical care than the elderly? N Engl J Med 1988;318: 1507-12.

16. Elofsson S, Unden AL, Krakau I. Patient charges-a hindrance to financially and psychosocially disadvantage groups seeking care. Soc Sci Med 1998; 46:1375-80.

17. Kiefe CI, Hyman DJ. Do public clinic systems provide health care access for the urban poor? A cross-sectional survey. J Community Health 1996; $21: 61-70$ 
18. Fiscella K. Is lower income associated with greater biopsychosocial morbidity? Implications for physicians working with underserved patients. J Fam Pract 1999;48:372-7.

19. Woolf SH, Rothemich SF, Johnson RE, Marsland DW. The functional status of inner-city primary care patients. Diminished function in a family practice population and its potential determinants. J Fam Pract 1998;47:312-5.

20. Miranda J, Azocar F, Komaromy M, Golding JM. Unmet mental health needs of women in publicsector gynecologic clinics. Am J Obstet Gynecol 1998;178:212-7.

21. Olfson M, Shea S, Feder A, et al. Prevalence of anxiety, depression, and substance use disorders in an urban general medicine practice. Arch Fam Med 2000;9:876-83.

22. Mauksch LB, Tucker SM, Katon WJ, et al. Mental illness, functional impairment, and patient preferences for collaborative care in an uninsured, primary care population. J Fam Pract 2001;50:41-7.

23. Cameron J, Mauksch L. Collaborative family health care in an uninsured primary care population: stages of integration. Fam Syst Health. 2002;20(4):343-63.

24. Mesa County. Our picture of health. Grand Junction, Colo: Civic Forum, 1998.

25. Spitzer RL, Kroenke K, Williams JB. Validation and utility of a self-report version of PRIME-MD: the PHQ primary care study. Primary Care Evaluation of Mental Disorders. Patient Health Questionnaire. JAMA 1999;282:1737-44.

26. Bernstein DP, Fink L. Childhood Trauma Questionnaire: A retrospective self-report. San Antonio: The Psychological Corporation, 1998.

27. Walker EA, Gelfand A, Katon WJ, et al. Adult health status of women with histories of childhood abuse and neglect. Am J Med 1999;107:332-9.

28. Wells KB, Sherbourne C, Schoenbaum M, et al. Impact of disseminating quality improvement programs for depression in managed primary care: a randomized controlled trial. JAMA 2000;283: 212-20.

29. Rosenblatt RA, Hart LG, Gamliel S, Goldstein B, McClendon BJ. Identifying primary care disciplines by analyzing the diagnostic content of ambulatory care. J Am Board Fam Pract 1995;8:34-45.

30. International classification of diseases, vols 1 and 2: clinical modification, 9th revision. 5th ed. Salt Lake City: Medicode, 1999.

31. Kroenke K, Spitzer RL, Williams JB, et al. Physical symptoms in primary care. Predictors of psychiatric disorders and functional impairment. Arch Fam Med 1994;3:774-9.

32. Katon $W$, Sullivan $M$, Walker E. Medical symptoms without identified pathology: relationship to psychiatric disorders, childhood and adult trauma, and personality traits. Ann Intern Med 2001;134(9 Pt 2): $917-25$.
33. Sturm R, Gresenz CR. Relations of income inequality and family income to chronic medical conditions and mental health disorders: national survey. BMJ 2002;324:20-3.

34. Gureje O, Von Korff M, Simon GE, Gater R. Persistent pain and well-being: a World Health Organization Study in Primary Care. JAMA 1998;280: 147-51.

35. Von Korff M, Simon G. The relationship between pain and depression. Br J Psychiatry Suppl 1996;30: 101-8.

36. Norquist GS, Regier DA. The epidemiology of psychiatric disorders and the de facto mental health care system. Annu Rev Med 1996;47:473-9.

37. Regier DA, Goldberg ID, Taube CA. The de facto US mental health services system: a public health perspective. Arch Gen Psychiatry 1978;35:685-93.

38. Sturm R, Wells K. Health insurance may be improving-but not for individuals with mental illness. Health Serv Res 2000;35(1 Pt 2):253-62.

39. Druss BG, Rosenheck RA. Mental disorders and access to medical care in the United States. Am J Psychiatry 1998;155:1775-7.

40. Ormel J, VonKorff M, Ustun TB, Pini S, Korten A, Oldehinkel T. Common mental disorders and disability across cultures. Results from the WHO Collaborative Study on Psychological Problems in General Health Care. JAMA 1994;272:1741-8.

41. Spitzer RL, Kroenke K, Linzer M, et al. Healthrelated quality of life in primary care patients with mental disorders. Results from the PRIME-MD 1000 Study. JAMA 1995;274:1511-7.

42. Katon $W$. The effect of major depression on chronic medical illness. Semin Clin Neuropsychiatry 1998; 3(2):82-6.

43. Ziegelstein RC, Fauerbach JA, Stevens SS, Romanelli J, Richter DP, Bush DE. Patients with depression are less likely to follow recommendations to reduce cardiac risk during recovery from a myocardial infarction. Arch Intern Med 2000;160:1818-23.

44. Ciechanowski PS, Katon WJ, Russo JE. Depression and diabetes: impact of depressive symptoms on adherence, function, and costs. Arch Intern Med 2000; 160:3278-85.

45. Lin EH, Simon GE, Katzelnick DJ, Pearson SD. Does physician education on depression management improve treatment in primary care? J Gen Intern Med 2001;16:614-9.

46. Lin EH, Katon WJ, Simon GE, et al. Achieving guidelines for the treatment of depression in primary care: is physician education enough? Med Care 1997; 35:831-42.

47. Committee on Quality of Health Care in America, Institute of Medicine. Crossing the quality chasm: a new health care system for the 21 st century. Washington, DC: National Academy Press, 2001.

48. Makoul G. Essential elements of communication in 
medical encounters: the Kalamazoo consensus statement. Acad Med 2001;76:390-3.

49. Stewart M, Brown JB, Donner A, et al. The impact of patient-centered care on outcomes. J Fam Pract 2000;49:796-804.

50. Stewart MA. Effective physician-patient communication and health outcomes: a review. CMAJ 1995; 152:1423-33.

51. White J, Levinson $W$, Roter D. "Oh, by the way ... ": the closing moments of the medical visit. J Gen Intern Med 1994;9:24-8.

52. Marvel MK, Epstein RM, Flowers K, Beckman HB. Soliciting the patient's agenda: have we improved? JAMA 1999;28:283-7.

53. Dugdale DC, Epstein R, Pantilat SZ. Time and the patient-physician relationship. J Gen Intern Med 1999;14(Suppl 1):S34-40.

54. Byrne P, Long B. Doctors talking to patients. London: Her Majesty's Stationery Office, 1976.

55. Hahn SR. Physical symptoms and physician-experienced difficulty in the physician- patient relationship. Ann Intern Med 2001;134(9 Pt 2):897-904.

56. Lin EH, Katon W, Von Korff M, et al. Frustrating patients: physician and patient perspectives among distressed high users of medical services. J Gen Intern Med 1991;6:241-6.

57. Mauksch L, Hillenburg L, Robins L. The establishing focus protocol: training for collaborative agenda setting and time management in the medical interview. Fam Syst Health 2001;19:147-57.

58. Kirmayer LJ, Robbins JM. Patients who somatize in primary care: a longitudinal study of cognitive and social characteristics. Psychol Med 1996;26:937-51.

59. Feder A, Olfson M, Gameroff M, et al. Medically unexplained symptoms in an urban general medicine practice. Psychosomatics 2001;42:261-8.

60. Kroenke K, Jackson JL, Chamberlin J. Depressive and anxiety disorders in patients presenting with physical complaints: clinical predictors and outcome. Am J Med 1997;103:339-47.

61. Pignone MP, Gaynes BN, Rushton JL, et al. Screening for depression in adults: a summary of the evidence for the U.S. Preventive Services Task Force. Ann Intern Med 2002;136:765-76.

62. Jackson JL, Kroenke K. The effect of unmet expectations among adults presenting with physical symptoms. Ann Intern Med 2001;134(9 Pt 2):889-97.

63. Marple RL, Kroenke K, Lucey CR, Wilder J, Lucas CA. Concerns and expectations in patients presenting with physical complaints. Frequency, physician perceptions and actions, and 2-week outcome. Arch Intern Med 1997;157:1482-8.

64. Dwight-Johnson M, Unutzer J, Sherbourne C, Tang L, Wells KB. Can quality improvement programs for depression in primary care address patient preferences for treatment? Med Care 2001;39:934-44.

65. Mauksch L. An evidenced-based recipe for primary care, psychotherapy and patient preferences: Response to "A systematic review of brief psychological therapies in primary health care." Fam Syst Health 2000;18:315-22.

66. Katz JN. Patient preferences and health disparities. JAMA 2001;286:1506-9.

67. Seaburn DB, Gawanski BA, Gunn WB Jr, Lorenz A, Mauksch L. Models of collaboration: a guide for mental health professionals working with physicians and health care practitioners. New York: Basic Books, 1996.

68. Blount A. Integrated primary care: the future of medical and mental health collaboration. New York: W. W. Norton, 1998.

69. Cummings NA, Cummings JL, Johnson JN, editors. Behavioral health in primary care: a guide for clinical integration. Madison, Wisc: Psychological Press, 1997.

70. Katon W, Von Korff M, Lin E, et al. Collaborative management to achieve depression treatment guidelines. J Clin Psychiatry 1997;58(Suppl 1):20-3.

71. Von Korff M, Katon W, Bush T, et al. Treatment costs, cost offset, and cost-effectiveness of collaborative management of depression. Psychosom Med 1998;60:143-9.

72. Schoenbaum M, Unutzer J, Sherbourne C, et al. Cost-effectiveness of practice-initiated quality improvement for depression: results of a randomized controlled trial. JAMA 2001;286:1325-30.

73. Simon GE, Katon WJ, VonKorff M, et al. Costeffectiveness of a collaborative care program for primary care patients with persistent depression. Am J Psychiatry 2001;158:1638-44.

74. Lin EH, VonKorff M, Russo J, et al. Can depression treatment in primary care reduce disability? A stepped care approach. Arch Fam Med 2000;9: 1052-8.

75. Simon GE, Revicki D, Heiligenstein J, et al. Recovery from depression, work productivity, and health care costs among primary care patients. Gen Hosp Psychiatry 2000;22:153-62.

76. Mental health: a report of the Surgeon General. Department of Health and Human Services. Available at: http://www.surgeongeneral.gov/library/ mentalhealth/home.html.

77. Von Korff M, Moore JC. Stepped care for back pain: activating approaches for primary care. Ann Intern Med 2001;134(9 Pt 2):911-7.

78. Kavanagh KT, Tate NP. Models to promote medical health care delivery for indigent families: computerized tracking to case management. J Health Soc Policy 1990;2:21-34.

79. Ferguson JA, Weinberger M. Case management programs in primary care. J Gen Intern Med 1998; 13:123-6.

80. Weich S, Lewis G. Poverty, unemployment, and common mental disorders: population based cohort study. BMJ 1998;317:115-9. 
81. Wagner EH, Austin BT, Von Korff M. Improving outcomes in chronic illness. Manag Care Q 1996; 4(2):12-25.

82. Katon W, Von Korff M, Lin E, et al. Populationbased care of depression: effective disease management strategies to decrease prevalence. Gen Hosp Psychiatry 1997;19:169-78.

83. Peek CJ, Heinrich R. Building a collaborative care organization: from idea to invention to innovation. Fam Syst Med 1995;13:327-42.

84. Stange KC, Zyzanski SJ, Jaen CR, et al. Illuminating the 'black box'. A description of 4,454 patient visits to 138 family physicians. J Fam Pract 1998;46:37789.

85. Schneeweiss R, Cherkin DC, Hart GL. The effect of including secondary diagnoses on the description of the diagnostic content of family practice. Med Care 1984;22:1058-63.

86. Barry CA, Bradley CP, Britten N, Stevenson FA,
Barber N. Patients' unvoiced agendas in general practice consultations: qualitative study. BMJ 2000; 320:1246-50.

87. Ryan RM, Deci EL. Self-determination theory and the facilitation of intrinsic motivation, social development, and well-being. Am Psychol 2000;55:68-78.

88. Williams G, Frankel R, Campbell T, Deci E. Research on relationship-centered care and healthcare outcomes from the Rochester Biosychosocial Program: a self-determination theory integration. Fam Syst Health 2000;18:79-90.

89. Bobak M, Pikhart H, Rose R, Hertzman C, Marmot M. Socioeconomic factors, material inequalities, and perceived control in self-rated health: cross-sectional data from seven post-communist countries. Soc Sci Med 2000;51:1343-50.

90. Moss N. Socioeconomic disparities in health in the US: an agenda for action. Soc Sci Med 2000;51: 1627-38. 